\title{
Corrigendum: Seismic Performance of Recycled Concrete Filled Circular Steel Tube Columns
}

\author{
Dingyi $X u^{1}$, Zongping Chen ${ }^{2,3 *}$ and Chunheng Zhou ${ }^{4 *}$ \\ ${ }^{1}$ The First People's Hospital of Lianyungang, Lianyungang, China, ${ }^{2}$ College of Civil Engineering and Architecture, Guangxi \\ University, Nanning, China, ${ }^{3}$ Guangxi Key Laboratory of Disaster Prevention and Engineering Safety, Guangxi University, Nanning, \\ China, ${ }^{4}$ School of Civil and Environmental Engineering, Ningbo University, Ningbo, China
}

Keywords: seismic performance, replacement percentage, column, recycled concrete filled circular steel tube, recycled concrete

\section{A Corrigendum on}

Seismic Performance of Recycled Concrete Filled Circular Steel Tube Columns

\section{OPEN ACCESS}

Approved by:

Frontiers Editorial Office,

Frontiers Media SA, Switzerland

${ }^{*}$ Correspondence: Zongping Chen zpchen@gxu.edu.cn

Chunheng Zhou

chzhou2014@hotmail.com

Specialty section:

This article was submitted to

Structural Materials,

a section of the journal

Frontiers in Materials

Received: 17 December 2021 Accepted: 21 December 2021

Published: 13 January 2022

Citation:

Xu D, Chen Z and Zhou C (2022) Corrigendum: Seismic Performance of Recycled Concrete Filled Circular Steel

Tube Columns.

Front. Mater. 8:838233.

doi: $10.3389 /$ fmats.2021.838233 by Xu, D., Chen, Z., and Zhou, C. (2020). Front. Mater. 7:612059. doi: 10.3389/fmats.2020.612059

There is an error in the Funding statement as published. The correct funder name is 'Zhejiang Provincial Natural Science Foundation of China under Grant No. LQ20E080003'. The corrected Funding statement can be found below:

\section{FUNDING}

This work was supported by the Systematic Project of Guangxi Key Laboratory of Disaster Prevention and Structural Safety (2019ZDK017), Key Project of Scientific Research and Development Fund of Kangda College of Nanjing Medical University (KD2018KYJJZD009), Training Fund for Young Talents of Lianyungang Maternal and Child Health Hospital (KY201910) and Zhejiang Provincial Natural Science Foundation of China under Grant No. LQ20E080003.

The authors apologize for this error and state that this does not change the scientific conclusions of the article in any way. The original article has been updated.

Publisher's Note: All claims expressed in this article are solely those of the authors and do not necessarily represent those of their affiliated organizations, or those of the publisher, the editors and the reviewers. Any product that may be evaluated in this article, or claim that may be made by its manufacturer, is not guaranteed or endorsed by the publisher.

Copyright (c) $2022 \mathrm{Xu}$, Chen and Zhou. This is an open-access article distributed under the terms of the Creative Commons Attribution License (CC BY). The use, distribution or reproduction in other forums is permitted, provided the original author(s) and the copyright owner(s) are credited and that the original publication in this journal is cited, in accordance with accepted academic practice. No use, distribution or reproduction is permitted which does not comply with these terms. 